\title{
Efficacy of nutritional treatment in patients with psoriasis: A case report
}

\author{
ANG PENG WONG ${ }^{1}$, TATIANA KALINOVSKY ${ }^{2}$, ALEKSANDRA NIEDZWIECKI ${ }^{2}$ and MATTHIAS RATH ${ }^{2}$ \\ ${ }^{1}$ Natural Harmony, 47301 Petaling Jaya, Selangor, Malaysia; ${ }^{2}$ Dr. Rath Research Institute, Santa Clara, CA 95050, USA
}

Received August 30, 2014; Accepted June 8, 2015

DOI: $10.3892 /$ etm.2015.2631

\begin{abstract}
Psoriasis is a chronic inflammatory skin disease characterized by thickened, silvery-scaled patches. There is currently no cure and treatments only attempt to reduce the severity of symptoms. This study reports the case of a 36-year-old female who presented to the clinic with severe psoriasis and had been treated with topical steroid cream for the past 14 years. After adherence to prescribed dietary changes for 6 months, including abundant intake of vegetables, minimal consumption of meat, and avoidance of junk food and sugar in food or drinks, as well as nutritional supplementation with Vitacor Plus, ProLysinC, VitaCforte and LysinC Drink mix, the patient experienced complete resolution of psoriatic patches on her body.
\end{abstract}

\section{Introduction}

Psoriasis is a chronic inflammatory skin disease characterized by thickened, silvery-scaled patches. It has been associated with inflammatory and immune mechanisms probably associated with a genetic predisposition that can be triggered by stress $(1,2)$. Psoriasis is one of the most common chronic inflammatory skin disorders, affecting $2 \%$ of the general population (3). Psoriasis can substantially affect quality of life of patients. Numerous different treatments are available, which may allow short-term improvement and long-term control of the disease, but these measures do not cure psoriasis (4). Treatments include topical applications, systemic therapies and phototherapy; while they can be effective, a number of treatments are associated with significant adverse effects. Thus, there is a requirement for effective affordable therapies with fewer side effects that address the causes of the disorder.

Psoriasis is considered to be a T-cell-mediated inflammatory skin disease, which is characterized by hyperproliferation and poor differentiation of epidermal keratinocytes. While susceptibility to psoriasis is inherited, the disease is influenced

Correspondence to: Dr Aleksandra Niedzwiecki, Dr. Rath Research Institute, 1260 Memorex Drive, Santa Clara, CA 95050, USA

E-mail: author@drrath.com

Key words: nutrients, psoriasis, case report by environmental factors, such as infections and stress (5). Diet has been suggested to be involved in the aetiology and pathogenesis of psoriasis $(6,7)$. Fasting periods, low-energy diets and vegetarian diets have been shown to improve psoriasis symptoms in certain studies (6), and diets rich in polyunsaturated fatty acids from fish oil have also shown beneficial effects (7). These diets modify the polyunsaturated fatty acid metabolism and influence the eicosanoid profile, so that inflammatory processes are suppressed (6,7).

\section{Case report}

Written informed consent was obtained from the patient. A 36 -year old female presented to the clinic with psoriasis since the age of 22. She stated that her outbreak of psoriasis originated on the scalp and slowly descended downward towards her feet. Eventually the psoriatic lesions covered a large extent of her body, with the exception of her face (Fig. 1). She had been prescribed topical steroid cream for the past 14 years. Possible cause could be due to usage of anti-dandruff shampoo (which contains coal tar) since teenage years. The patient stopped using the anti-dandruff shampoo upon the first consultation. Stopping the shampoo would not alleviate psoriasis in the time limits of the present study, but may help hasten the recovery.

At the start of treatment, the patient was advised to consume a healthy diet with abundant vegetables, minimal meat, no junk food, and to avoid taking any forms of sugar in food or drinks. The following supplements were prescribed: Vitacor Plus-1 tablet 3 times daily, ProLysinC-2 tablets 3 times daily, VitaCforte-2 tablet 3 times daily, and LysinC Drink mix-1 scoop 4 times daily. Table I shows the list of components in these supplements. The patient was advised to stop using the steroid cream immediately at the beginning of treatment. Return appointments were scheduled once per month.

During the first month the patient experienced flaring of the skin condition with shedding of the dead skin. From the second month onwards, the psoriasis patches appeared thinner. Patches on the upper part of body (neck, shoulder, upper arms) appeared to heal faster than the lower parts of the body. This healing process continued and the psoriatic patches on the legs were the last to heal. At the end of 6 months the patient's psoriasis had completely disappeared (Fig. 2). The patient reported aggravation of itching and soreness in the first month, followed by gradual improvement of these symptoms over the 6 months. 
Table I. Nutritional supplements.

\begin{tabular}{|c|c|c|c|}
\hline Supplement regimen & $\begin{array}{l}\text { Nutrient amount in } \\
\text { each tablet/scoop }\end{array}$ & Supplement regimen & $\begin{array}{l}\text { Nutrient amounts in } \\
\text { each tablet/scoop }\end{array}$ \\
\hline Vitamin C obtained from: & & Citric bioflavonoids & $150 \mathrm{mg}$ \\
\hline Ascorbic acid & $76.7 \mathrm{mg}$ & \multicolumn{2}{|l|}{ LysinC Drink mix-1 scoop 4 times daily } \\
\hline Ascorbyl palmitate & $56.7 \mathrm{mg}$ & \multirow{2}{*}{\multicolumn{2}{|c|}{$\begin{array}{l}\text { Vitamin } \mathrm{C} \text { (ascorbic acid, calcium ascorbate, } 1,000 \mathrm{mg} \\
\text { magnesium ascorbate) }\end{array}$}} \\
\hline Calcium ascorbate & $33.3 \mathrm{mg}$ & & \\
\hline Magnesium ascorbate & $33.3 \mathrm{mg}$ & Calcium (calcium ascorbate) & $48 \mathrm{mg}$ \\
\hline Vitamin E (D- $\alpha$-tocopherol) & $29.1 \mathrm{mg}$ & Magnesium (magnesium ascorbate) & $34 \mathrm{mg}$ \\
\hline Vitamin $\mathrm{A}(\beta$ carotene $)$ & $158.4 \mu \mathrm{g} \mathrm{RE}$ & L-lysine (L-lysine $\mathrm{HCl})$ & $1,000 \mathrm{mg}$ \\
\hline Vitamin B1 & $2.3 \mathrm{mg}$ & Citric bioflavonoids & $200 \mathrm{mg}$ \\
\hline Vitamin B2 & $2.3 \mathrm{mg}$ & & \\
\hline Vitamin B3 & $15.0 \mathrm{mg}$ & \multicolumn{2}{|l|}{ RE, retinol equivalents. } \\
\hline Vitamin B5 & $13.3 \mathrm{mg}$ & & \\
\hline Vitamin B6 & $3.3 \mathrm{mg}$ & & \\
\hline Vitamin B12 & $6.7 \mu \mathrm{g}$ & & \\
\hline Vitamin D3 & $1.1 \mu \mathrm{g}$ & & \\
\hline Folic acid & $30.0 \mu \mathrm{g}$ & & \\
\hline Biotin & $21.7 \mu \mathrm{g}$ & & \\
\hline L-proline & $36.7 \mathrm{mg}$ & & \\
\hline L-lysine & $36.7 \mathrm{mg}$ & & \\
\hline L-carnitine & $11.7 \mathrm{mg}$ & & \\
\hline L-arginine & $13.3 \mathrm{mg}$ & & \\
\hline
\end{tabular}

L-cysteine

$11.7 \mathrm{mg}$

Calcium

Magnesium

$18.3 \mathrm{mg}$

$12.7 \mathrm{mg}$

Potassium $\quad 6.7 \mathrm{mg}$

Zinc $2.3 \mathrm{mg}$

Manganese $\quad 433.3 \mu \mathrm{g}$

Copper $\quad 110.0 \mu \mathrm{g}$

Selenium $\quad 6.7 \mu \mathrm{g}$

Chromium $\quad 3.3 \mu \mathrm{g}$

Molybdenum $\quad 1.3 \mu \mathrm{g}$

Inositol $11.7 \mathrm{mg}$

Coenzyme Q10 $2.3 \mathrm{mg}$

Phosphorus $\quad 5.0 \mathrm{mg}$

Pycnogenol $2.3 \mathrm{mg}$

Citrus biofl avonoids $\quad 33.3 \mathrm{mg}$

Additional natural vitamin E $\quad 2.6 \mathrm{mg}$

( $\beta$ -,$\gamma$ - and $\Delta$-tocopherol)

Additional natural carotenoids

$22.83 \mu \mathrm{g}$

( $\alpha$-carotene, lutein, zeaxanthin

and cryptoxanthin)

ProLysinC-2 tablets 3 times daily

Vitamin $\mathrm{C}$ obtained from:

Ascorbic acid

$300 \mathrm{mg}$

L-proline $150 \mathrm{mg}$

L-lysine $\quad 300 \mathrm{mg}$

VitaCforte-2 tablets 3 times daily

Vitamin C obtained from:

Ascorbic acid

Calcium ascorbate

Magnesium ascorbate

Ascorbyl palmitate

$150 \mathrm{mg}$

$150 \mathrm{mg}$

$67 \mathrm{mg}$

Table I. Continued. 
immunomodulators, burning sensation (5). Epidemiological studies have shown that increased intake of fresh fruits and vegetables is associated with a decreased prevalence of psoriasis $(8,9)$. In his review of the literature, Wolters cites evidence of a potential benefit of dietary factors in psoriasis (9); it was reported that fasting periods, low-energy diets, vegetarian diets, and diets rich in n-3 polyunsaturated fatty acids from fish, improved the symptoms of psoriasis, as these diets were able to suppress inflammatory processes. In an Italian case-control study of 316 patients with psoriasis and 366 controls, the risk of psoriasis was found to be significantly inversely associated with the intake of carrots, tomatoes and fresh fruit, as well as with the $\beta$-carotene intake (7). The consumption of vegetables and fruits may be beneficial in psoriasis due to their high content of various antioxidants, such as carotenoids, flavonoids and vitamin C. Frei (10) reports that increasing intake of antioxidants, such as vitamin $C$, vitamin $E, \beta$-carotene and selenium may aid in preventing an imbalance between oxidative stress and antioxidant defence in psoriasis.

The present case had presented with severe psoriasis showed complete clearing of patches after six months on the prescribed dietary and nutritional supplement treatment. In addition to the changes made to the diet, including increased vegetable and fruit intake, the added supplements also provided support against oxidative stress (with vitamins E, C, B2 and zinc and selenium), aided normal energy metabolism (with vitamins B1, B2, B3, B5, B6, B12 and biotin, magnesium and vitamin $\mathrm{C}$ ), maintained normal function of the immune system (with folic acid, vitamins A, D, and C, and selenium and copper); and optimized collagen formation (with vitamin $\mathrm{C}$, lysine and proline). In addition, the major components of the supplements, ascorbic acid, lysine and proline, have been shown to be important in collagen integrity $(11,12)$. Optimal collagen structure depends upon adequate supplies of ascorbic acid and the amino acids lysine and proline $(11,12)$. In addition, lysine contributes to extracellular matrix stability as a natural inhibitor of plasmin-induced proteolysis (11). Since the human body cannot synthesize vitamin $\mathrm{C}$ or the amino acid lysine, they are required in the diet.

In conclusion, the nutritional dietary change and supplementation with specific nutrients resolved the patient's psoriasis in six months. In contrast to the current treatments, which are associated with various side effects that only attempt to reduce the severity of symptoms, non-toxic nutritional dietary intervention was shown to be effective in resolving the patient's psoriasis, suggesting that this treatment approach should be considered for patients with psoriasis.

\section{Note added post-publication}

We received an email from a concerned reader regarding the claims made in the above paper that a patient experienced resolution of psoriatic patches on her body after having received a cocktail of nutritional supplements, while adhering to a regimen that prescribed dietary changes for a period of 6 months. Although the findings, while preliminary in nature, were potentially encouraging, the Editor agrees with the reader that the study exhibited a number of limitations. A follow-up study was not conducted, and the possibility of disease recurrence was not investigated. A follow-up study of the patient examined would also have demonstrated the effectiveness of this therapy over a long-term period. Moreover, since the present study was a case report, the findings reflect the response of an isolated patient incident. Clinical studies with a larger sample size would offer clearer insights in the efficacy of this therapy, allowing the statistical determination of clinical outcomes and benefits. Finally, the Editor also noted that the study contained an undeclared potential conflict of interest, since the nutritional supplements Vitacor Plus, ProLysinC, VitaCforte and LysinC Drink mix are sold by a company owned by Stichting Administratiekantoor Dr. Rath Holding, to whose companies group the sponsor of the study also belongs, and therefore there are commercial and financial implications associated with this case report.

\section{Funding}

This study was funded by the Dr. Rath Health Foundation (Santa Clara, CA, USA), a non-profit organization.

\section{Competing interests}

Note that the nutritional supplements described in this case report were manufactured for Dr. Rath International, Inc., owned by Dr. Rath Holding. Dr Rath is one of the contributing authors.

\section{References}

1. Feldman SR: A quantitative definition of severe psoriasis for use in clinical trials. J Dermatolog Treat 15: 27-29, 2004.

2. Zachariae R, Zachariae H, Blomqvist K, Davidsson S, Molin L, Mørk C and Sigurgeirsson B: Self-reported stress reactivity and psoriasis related stress of Nordic psoriasis sufferers. J Eur Acad Dermatol Venereol 18: 27-36, 2004.

3. Christophers E: Psoriasis-epidemiology and clinical spectrum. Clin Exp Dermatol 26: 314-20, 2001.

4. Naldi L, Svensson A, Diepgen T, Elsner P, Grob JJ, Coenraads PJ, Bavinck JN and Williams H; European Dermato-Epidemiology Network: Randomized clinical trials for psoriasis 1977-2000: The EDEN survey. J Invest Dermatol 120: 738-41, 2003.

5. Brown AC, Hairfield M, Richards DG, McMillin DL, Mein EA and Nelson CD: Medical nutrition therapy as a potential complementary treatment for psoriasis - five case reports. Altern Med Rev 9: 297-307, 2004.

6. Naldi L, Parazzini F, Peli L, Chatenoud L and Cainelli T: Dietary factors and the risk of psoriasis. Results of an Italian case-control study. Br J Dermatol 134: 101-106, 1996.

7. Kragballe K and Fogh K: A low-fat diet supplemented with dietary fish oil (Max-EPA) results in improvement of psoriasis and in formation of leukotriene B5. Acta Derm Venereol 69: 23-28, 1989.

8. Kavli G, Forde OH, Arnesen E and Stenvold SE: Psoriasis: familial predisposition and environmental factors. Br Med J (Clin Res Ed) 291: 999-1000, 1985.

9. Wolters M: Diet and psoriasis: experimental data and clinical evidence. Br J Dermatol 153: 706-714, 2005.

10. Frei B: On the role of vitamin C and other antioxidants in atherogenesis and vascular dysfunction. Proc Soc Exp Biol Med 222: 196-204, 1999. Rath M and Pauling L: Plasmin $\square$ induced proteolysis and the role 104 of apoprotein (a), lysine and synthetic analogs. Orthomolecular 105 Med 7: 17ロ23, 1992.

11. Cha J, Roomi MW, Ivanov V, Kalinovsky T, Niedzwiecki A 106 and Rath M: Ascorbate supplementation inhibits growth and 107 metastasis of $\mathrm{B} 16 \mathrm{FO}$ melanoma and $4 \mathrm{~T} 1$ breast cancer cells in 108 vitamin C $\square$ deficient mice. Int J Oncol 42: 55 $\square 64,2013$.

12. Rath M and Pauling L: Plasmin-induced proteolysis and the role of apoprotein (a), lysine and synthetic analogs. Orthomolecular Med 7: 17-23, 1992.

13. Cha J, Roomi MW, Ivanov V, Kalinovsky T, Niedzwiecki A and Rath M: Ascorbate supplementation inhibits growth and metastasis of B16FO melanoma and 4T1 breast cancer cells in vitamin C-deficient mice. Int J Oncol 42: 55-64, 2013. 